\title{
Long-term Outcomes of Children with Cow's Milk Protein Allergy in a Pediatric Allergy Clinic
}

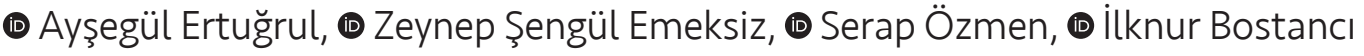 \\ University of Health Sciences Turkey, Ankara Dr. Sami Ulus Maternity and Children Training and Research Hospital, Clinic of Pediatric Allergy and \\ Immunology, Ankara, Turkey
}

\begin{abstract}
Aim: This study aimed to assess the clinical features, management, and long-term outcomes of pediatric patients with cow's milk protein allergy (CMPA).

Materials and Methods: This is a retrospective study consisting of 246 children with CMPA. Data of the patients were collected from the medical files.

Results: $95.8 \%$ of patients experienced the first reactions associated with cow's milk (CM) allergy during infancy. Hen's egg (56\%) was the most frequent triggering food coexisting with CMPA, and this was followed by tree nuts (6\%), wheat (5\%) and lentil (3\%). During five years of the follow-up period, tolerance occurred in $78.9 \%$ of the patients. The optimal cutoff value for CM slgE to predict the tolerance status for CMPA was $7.39 \mathrm{kU} / \mathrm{L}$ with a sensitivity of $87.3 \%$ and a specificity of $58.3 \%$, [95\% confidence intervals (CI), 0.655-0.859, p<0.001]. IgE-mediated hypersensitivity reactions [odds ratios (OR) 4,369 (95\% Cl, 2,298-8,308), $\mathrm{p}<0.001$ ], family history of atopy [OR 2,943 (95\% Cl, 1,324-6,541), p: 0.008), CM slgE $>7.39$ [OR 9,683 (95\% Cl, 3,947-23,757), p<0.001], casein slgE $>0.56$ [OR 6,909 (95\% Cl, 2,719-17,557), $p<0.001]$, were the predictors for the persistence.

Conclusion: This study showed that the majority of the CMPA in children gave rise to clinical manifestations in the infancy period, most of them less than six months of age. The prognosis of the disease was favorable with a spontaneous tolerance developed by the age of three in most patients. IgE-mediated hypersensitivity reactions, a family history of atopy and higher specific IgE values were predictive factors for the long-lasting disease.
\end{abstract}

Keywords: Cow's milk allergy, cow's milk protein allergy, children, skin prick test, tolerance

\section{Introduction}

Cow's milk protein allergy (CMPA) is the most common food allergy in children with a prevalence ranging between $1.8 \%-7.5 \%$ (1). CMPA presents with a variety of symptoms involving different systems according to the type of reaction, with a predominance of IgE-mediated reactions. Skin reactions are the most common presentations of CMPA, followed by gastrointestinal and respiratory symptoms. A detailed history, physical examination, skin prick test (SPT) and specific IgE testing may support the diagnosis, but oral food challenge (OFC) is the gold standard for CMPA diagnosis (2). Treatment is the elimination of the dairy products from the infants' diet and if necessary, from the maternal diet in breastfed infants. The majority of patients outgrow their allergy during childhood in the natural course

\section{Address for Correspondence}

Illknur Bostancı, University of Health Sciences Turkey, Ankara Dr. Sami Ulus Maternity and Children Training and Research Hospital, Clinic of Pediatric Phone: +90 3123056314 E-mail: ilknurbirol@hotmail.com ORCID: orcid.org/0000-0001-6392-5877 Received: 03.08.2020 Accepted: 29.09.2020

${ }^{\circ}$ Copyright 2021 by Ege University Faculty of Medicine, Department of Pediatrics and Ege Children's Foundation The Journal of Pediatric Research, published by Galenos Publishing House. 
of the disease with a favorable prognosis in general (3). Different factors seem to affect the acquisition of this immune tolerance (4). With different rates of resolution and different predictors reported for the tolerance, the natural history of CMPA and strategies for inducing tolerance may change over time $(3,5)$.

In this study, we aimed to assess the natural course of CMPA by investigating its clinical features, management, and the long-term outcomes in pediatric patients with CMPA.

\section{Materials and Methods}

\section{Study Population}

Ours is a retrospective study of 246 children with CMPA treated between January 2014 and February 2016 at the Department of Pediatric Allergy Immunology in the University of Health Sciences Turkey, Ankara Dr. Sami Ulus Maternity and Child Training and Research Hospital. Data were collected from the medical files. CMPA is classified by the underlying immune mechanism (IgE-mediated, nonIgE-mediated and mixed), the time of presentation and organ system involvement. Reactions within minutes to 2 hours of exposure are considered to be IgE-mediated, while reactions in hours are considered to be non-lgEmediated or a mix of both $(1,2,6)$. Food allergy diagnosis was based on a combination of clear-cut history, typical clinical presentation and an OFC test. Children were diagnosed with CMPA according to the international guidelines $(1,2,7)$.

\section{Study Measurement}

Atopy was evaluated by SPT, prick to prick test (PTP) and slgE measurements. Initially, a panel of major food [CM, hen's egg (HE), wheat, soy, walnut, hazelnut and peanut] standardized allergen extracts (Stallergens, SA, Antony, France) and fresh milk (FM) were used for skin tests on those patients presenting with suspected food allergy. Individually, the allergen panel was enhanced according to the patient's clinical reactions and diet history. SPTs with inhalant allergens (grass, weed, and tree) (Stallergenes, SA, Antony, France) were performed on children older than two years. A positive SPT was defined as a wheal size of $\geq 3$ $\mathrm{mm}$ compared to the negative control. Specific IgE serum levels to food allergens were measured with an enzyme immunoassay system (IMMULITE Siemens, Germany). slgE levels greater than $0.35 \mathrm{kUA} / \mathrm{L}$ were considered as positive.

\section{Oral Food Challenge}

Children underwent OFC for diagnostic challenge and determination of tolerance acquisition with CM based on the guidelines' recommendations (8). The age of immunotolerance is defined as the time when FM was tolerated for the first time.

\section{Statistical Analysis}

The Statistical Package for Social Sciences (SPSS) version 15 (SPSS Inc., Chicago, IL, USA) was used for the statistical analysis of the research data. Odds ratios (OR) with appropriate $95 \%$ confidence intervals $(\mathrm{Cl})$ were calculated by logistic regression analyses. Receiver operating characteristic (ROC) curve analysis was performed to identify the optimal cut-off CM and casein slgE value to predict the tolerance status for CMPA. Positive predictive values (PPV), negative predictive values (NPV), sensitivity and specificity values were determined. Statistical significance was defined at $\mathrm{p}<0.05$.

Ethical approval was received from the University of Health Sciences Turkey, Ankara Dr. Sami Ulus Maternity and Child Training and Research Hospital local institutional review board (approval number: 2016/2519). Informed consent was not required because the study was conducted retrospectively.

\section{Results}

A total of 246 patients with a diagnosis of CMPA were enrolled in this study. The characteristics of the study population are shown in Table I. The diagnoses of CM allergies were as follows: IgE-mediated in 84 (34.1\%), nonIgE mediated in 36 (14.6\%), and mixed-type in 126 (51.2\%) patients. $95.8 \%$ of the patients experienced their first reactions associated with $C M$ allergy during infancy ( $\leq 12$ months). The diagnoses for the 246 cases of CM allergy are shown in Figure 1. Skin symptoms (83.7\%) were the most frequently observed clinical manifestation followed by gastrointestinal system (GIS) (17\%), respiratory system (6\%) and cardiovascular system (1\%) involvements. After the ingestion of dairy product by our study group, the most frequently observed symptoms were eczema (49.5\%) for skin involvement, blood and/or mucus-streaked stools (11.7\%) for the GIS and cough and wheezing (4.8\%) for the respiratory system. $12.1 \%(n=30)$ of the patients had anaphylaxis with CM, and $4.4 \%(n=11)$ of the patients had anaphylaxis with foods other than CM.

The dairy products consumed at the time of the first hypersensitivity reaction were CM-based formula (31.5\%), yogurt (23\%), breast milk (23), CM (11.9\%), cheese $(9.4 \%)$, butter $(0.9 \%)$ and condensed CM $(0.4 \%)$. At the time of the diagnosis, $81.9 \%$ of the patients were breastfed (with or without complementary feeding or CM-based formula). 
Table I. Characteristics of the study population

\begin{tabular}{|c|c|}
\hline & Study population $(\mathrm{N}=246)$ \\
\hline $\begin{array}{l}\text { Gender } \\
\text { Male } \\
\text { Female }\end{array}$ & $\begin{array}{lc}162 & (65.8 \%) \\
84 & (34.2 \%)\end{array}$ \\
\hline Current age, median (IQR), months & $54 \quad(43-62)$ \\
\hline Age of the onset of the allergic symptoms to $C M$, median (IQR), months & $4 \quad(2-6)$ \\
\hline Age at the diagnosis of CM allergy, median (IQR), months & $6 \quad(4-7)$ \\
\hline Food allergy other than CM, no (\%) & $142(57.7 \%)$ \\
\hline $\begin{array}{l}\text { Presence of allergic diseases, no (\%) } \\
\text { Atopic dermatitis } \\
\text { Allergic rhinitis } \\
\text { Asthma }\end{array}$ & $\begin{array}{ll}122 & (49.5 \%) \\
12 . & (4.8 \%) \\
39 & (15.9 \%)\end{array}$ \\
\hline Accompanying inhalant allergen sensitization, no (\%) & $12 \quad(4.9 \%)$ \\
\hline Family history of atopy, no (\%) & $115(46.7 \%)$ \\
\hline Total IgE, median (IQR), kU/L & $40 \quad(19.4-104)$ \\
\hline *slgE CM at the time of diagnosis, median (IQR), kU/L & $0.3(0-2.8)$ \\
\hline${ }^{*}$ slgE Casein at the time of diagnosis, median (IQR), kU/L & $0.1(0-1.5)$ \\
\hline SPT with cow's milk extract at the time of diagnosis, median (IQR), mm & $2 \quad(0-5)$ \\
\hline PTP with fresh cow's milk at the time of diagnosis, median (IQR), mm & $6 \quad(0-10)$ \\
\hline Vitamin D level (total 25[OH]D), median (IQR), ng/mL & $27 \quad(18.5-39.6)$ \\
\hline
\end{tabular}

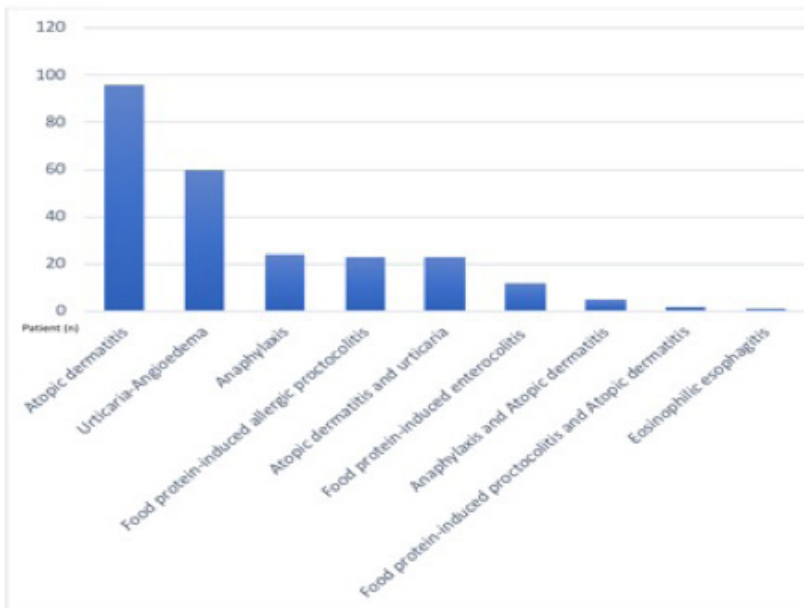

Figure 1. Diagnosis of cow's milk protein allergy

Those patients who were formula-fed on at least one occasion were $39.2 \%$ of the population. The patients were introduced to complementary foods at a mean age of 5 months (range: 1 to 9 months).

Multiple food allergies were determined in 57.7\% ( $n=142)$ of the patients. The most common food allergy other than CM was HE $(n=138)$. The concomitant food allergies are shown in Figure 2.

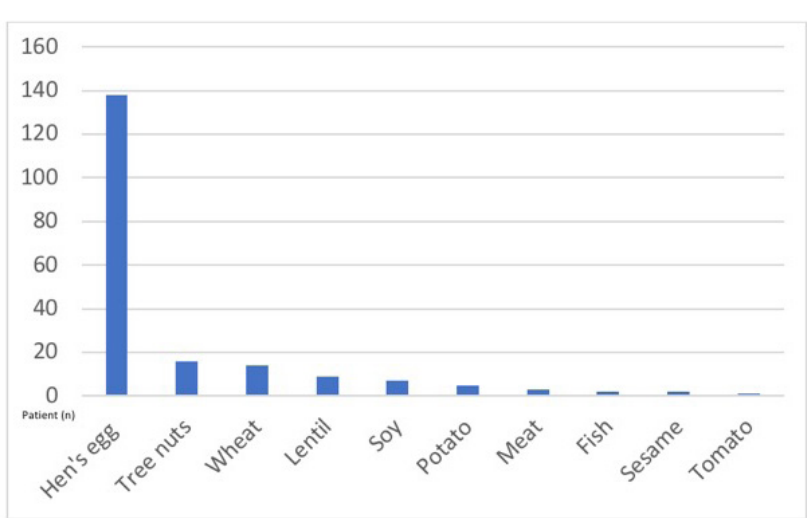

Figure 2. Food allergy other than cow's milk

At the time that the first SPTs were performed, 70.3\% of the patients' PTP performed with FM were found to be positive; however, $46.5 \%$ of the patients' SPT with CM were positive. SPT performed with goat's milk was positive in $62.7 \%$ of the patients.

During the elimination of CM and its products from the diet, $62.5 \%$ of the patients used extensively hydrolyzed infant formula (eHF) or amino acid-based formula (AAF) with a mean ( \pm standard deviation) duration of $11( \pm 5.9)$ months. Among those mothers who were on an elimination 
diet for CM and its products, $77.3 \%$ received supplemental calcium and vitamin $\mathrm{D}$. The vitamin $\mathrm{D}$ level of the patients evaluated during the follow-up period was below $20 \mathrm{ng} / \mathrm{mL}$ in $30.3 \%$ of the patients.

Approximately within five years of follow-up period, tolerance occurred in $78.9 \%$ of the patients $(61.9 \%$ IgEmediated and $87.6 \%$ non-IgE-mediated). $59.3 \%$ of the patients developed tolerance by the age of 24 months, and $68.2 \%$ by the age of 36 months. ROC curve analysis was performed to identify the optimal cut-off $C M$ and casein sIgE values to predict the tolerance status for CMPA. (Figures 3 and 4). The optimal cut-off value for final CM slgE was $7.39 \mathrm{kU} / \mathrm{L}$ with a sensitivity of $87.3 \%$ and a specificity of $58.3 \%$, as well as an area under the curve of 0.757 $(95 \% \mathrm{Cl}, 0.655-0.859, \mathrm{p}<0.001)$ (Table II). The type of the hypersensitivity reaction, family history of atopy, age of the introduction of complementary feeding, CM slgE, casein slgE, wheal size of SPT with CM and wheal size of PTP with FM were associated with tolerance status $(p<0.05)$. The comparison of patients with CMPA according to their status of tolerance or persistence is shown in Table III. IgEmediated hypersensitivity reactions [OR 4,369 $(95 \% \mathrm{Cl}$, $2,298-8,308), p<0.001]$, family history of atopy [OR 2,943 $(95 \% \mathrm{Cl}, 1,324-6,541), \mathrm{p}=0.008$ ], CM slgE $>7.39$ [OR 9,683

Table II. ROC analysis and diagnostic value of cow's milk and casein spesific IgE for the prediction of the tolerance in patients with cow's milk protein allergy

\begin{tabular}{|l|l|l|l|l|l|l|l|l|}
\hline & \multicolumn{2}{|l}{ Diagnostic scan } & \multicolumn{2}{l|}{ ROC curve } \\
\cline { 2 - 9 } & Cut-off & Sensitivity\% & Specificity\% & PPV\% & NPV\% & AUC & $\mathbf{9 5 \%}$ Cl lower-upper & p-value \\
\hline $\begin{array}{l}\text { CM-specific IgE final } \\
\text { kU/L }\end{array}$ & $\leq 7.39$ & 87.37 & 58.33 & 84.69 & 63.64 & $\mathbf{0 . 7 5 7}$ & $0.655-0.859$ & $\mathbf{0 . 0 0 1}$ \\
\hline $\begin{array}{l}\text { Casein spesific IgE final } \\
\text { kU/L }\end{array}$ & $\leq 0.56$ & 63.33 & 80.00 & 89.06 & 45.90 & $\mathbf{0 . 7 5 8}$ & $0.651-0.865$ & $\mathbf{0 . 0 0 1}$ \\
\hline
\end{tabular}

ROC: Receiver operating characteristic, CM: Cow's milk, PPV: Positive predictive values, NPV: Negative predictive values, AUC: Area under the curve, CI: Confidence interval

Table III. Comparison of the patients with cow's milk protein allergy according to the status of tolerance or persistence

\begin{tabular}{|c|c|c|c|}
\hline & $\begin{array}{l}\text { Tolerant patients } \\
\mathrm{N}=194\end{array}$ & $\begin{array}{l}\text { Persistent patients } \\
\mathrm{N}=52\end{array}$ & p-value \\
\hline $\begin{array}{l}\text { Gender } \\
\text { Male, no (\%) } \\
\text { Female, no (\%) }\end{array}$ & $\begin{array}{l}131(67.5 \%) \\
63(32.5 \%)\end{array}$ & $\begin{array}{l}31(59.6 \%) \\
21(40.3 \%)\end{array}$ & 0.285 \\
\hline Current age (years), median (IQR), months & $55(46-62)$ & $50(27-64)$ & 0.014 \\
\hline Age at onset of symptoms & $6(3-7)$ & $6(5-8)$ & 0.182 \\
\hline $\begin{array}{l}\text { Age of the introduction of complementary feeding, } \\
\text { mean }( \pm S D) \text {, months }\end{array}$ & $4.9( \pm 1.4)$ & $5.4( \pm 0.8)$ & 0.022 \\
\hline $\begin{array}{l}\text { Type of hypersensitivity reaction } \\
\text { IgE-mediated, no (\%) } \\
\text { Non-IgE-mediated or mixed type, no (\%) }\end{array}$ & $\begin{array}{l}52(26.8 \%) \\
142(73.2 \%)\end{array}$ & $\begin{array}{l}32(61.5 \%) \\
20(38.5 \%)\end{array}$ & $<0.001$ \\
\hline $\begin{array}{l}\text { Concomitant food allergy } \\
\text { Single food allergy, no (\%) } \\
\text { Multiple food allergy, no (\%) }\end{array}$ & $\begin{array}{l}84(43.4 \%) \\
110(56.7 \%)\end{array}$ & $\begin{array}{l}20(38.5 \%) \\
32(61.5 \%)\end{array}$ & 0.531 \\
\hline Family history of atopy, no (\%) & $80(41.2 \%)$ & $35(67.3 \%)$ & 0.007 \\
\hline CM slgE initial, median (IQR), kU/L & $0.10(0-1.10)$ & $2.6(0.1015 .65)$ & $<0.001$ \\
\hline CM slgE final, median (IQR), kU/L & $0.54(0-4.8)$ & $13.06(1.64-85.45)$ & $<0.001$ \\
\hline Casein slgE initial, median (IQR), kU/L & $0(0-0.69)$ & $0.69(0-7.6)$ & 0.868 \\
\hline Casein slgE final, median (IQR), kU/L & $0.16(0-1.8)$ & $4.5(0.7-35.1)$ & $<0.001$ \\
\hline SPT with cow's milk extract, median (IQR), mm & $0(0-5)$ & $5(0-7)$ & 0.004 \\
\hline PTP with fresh cow's milk, median (IQR), mm & $5(0-9)$ & $8(6-11)$ & $<0.001$ \\
\hline Vitamin D level [total 25(OH)D], median (IQR), ng/mL & $26.8(18.9-38)$ & $28.1(15.8-43.2)$ & 0.911 \\
\hline
\end{tabular}




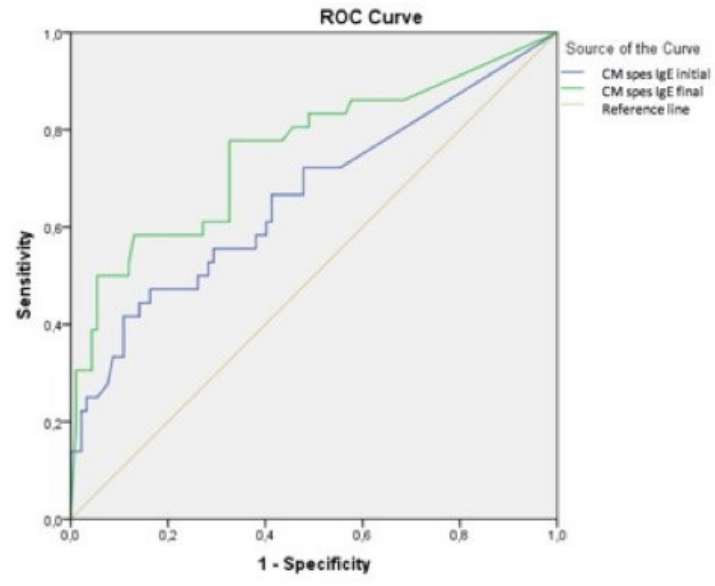

Figure 3. Receiver operating characteristic curve analysis for estimating the optimal cut-off cow's milk slgE value

ROC: Receiver operating characteristic, CM: Cow's milk, slgE: Specific IgE

(95\% Cl, 3,947-23,757), $\mathrm{p}<0.001]$, and casein slgE $>0.56$ [OR $6,909(95 \% \mathrm{Cl}, 2,719-17,557), \mathrm{p}<0.001]$ were associated with longer-lasting disease.

\section{Discussion}

This study emphasized the early onset of the symptoms in CMPA, particularly in the first six months of infancy with most of the children presenting with AD. Among the initial diagnostic allergy tests, PTP performed with FM showed higher positivity when compared to SPT with CM. Lentil was one of the prominent triggering foods coexisting with CMPA after $\mathrm{HE}$, tree nuts and wheat. Our study population showed that more than half of the patients developed tolerance by the age of 36 months with a favorable prognosis for CMPA. An earlier introduction of complementary feeding and having non-IgE-mediated or mixed type reaction showed a positive association with the development of tolerance in children with CMPA. Higher CM and casein-specific IgE level, family history of atopy and IgE-mediated reactions showed a negative association with tolerance.

CMPA is more common in infants and peaks in the first year of life with a predominance of the IgE-mediated type of allergy (3). Nearly half of the children with CMPA are estimated to have IgE-mediated reactions (9). In the current study, the median (IQR) age of symptom onset was four months (2-6) which was distinctly earlier than reported in a preliminary analysis of a Turkish national multicenter study of children diagnosed with food allergy (10). In our study population, the mixed group and non-IgEmediated reactions were more common than IgE-mediated reactions. In a study of pediatric patients with CMPA from Turkey, the authors reported more IgE referenced diagnoses

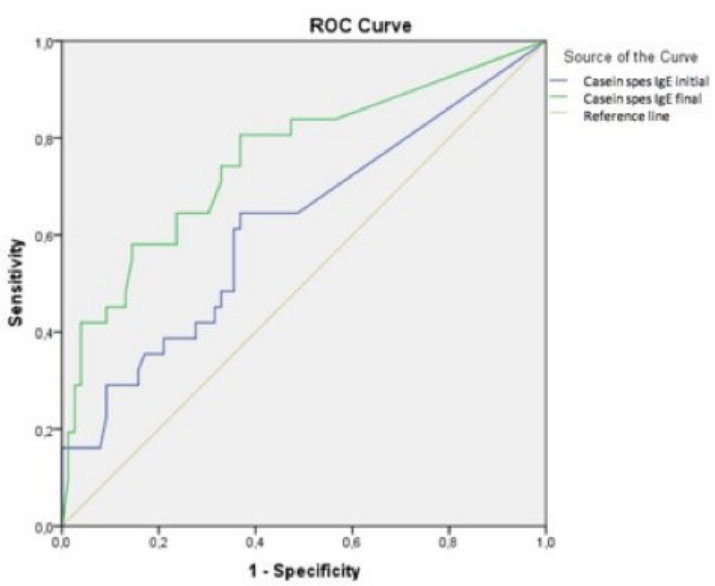

Figure 4. Receiver operating characteristic curve analysis for estimating the optimal cut-off casein slgE value

ROC: Receiver operating characteristic, slgE: Specific IgE

(66.6\%) when compared to non-IgE and the mixed group (11). However, Yang et al. (12). reported that the majority of CMPA infants had eczema in China. Approximately one-third of children with AD had a diagnosis of CMPA after OFC, and nearly $40-50 \%$ of children less than one year of age with CMPA also had AD (13). We would like to emphasize the main clinic presentation of CMPA in our study population which was AD rather than IgE-mediated reactions like urticaria or angioedema during the first six months of infancy.

The clinical presentation of CMPA involved cutaneous symptoms in up to $90 \%$, Gl symptoms in up to $60 \%$, respiratory symptoms in up to $30 \%$ and anaphylaxis in 0.8 to $9 \%$ of cases (9). Symptoms and signs related to CMPA involved mostly the skin and the Gl system in our study group which is consistent with the literature; the anaphylaxis rate was slightly higher than those reported (9).

In studies reported from Turkey, about $30-50 \%$ of food allergic children have multiple food allergies (2). In the current study, the rate of multiple food allergies is within the upper limits. HE was the most frequent triggering food coexisting with CMPA similar to the literature, followed by tree nuts and wheat. The third and fourth most common triggering foods differ from one country to another such as peanuts in the USA and Switzerland, wheat in Germany and Japan, sesame in Israel, walnuts in Korea and hazelnuts in Turkey (3). The fourth most common food in our group was lentil, followed by soy, potato and meat. We consider that these differences are related to the frequency of consumption of these foods in specific regions, a variety of the dietary patterns and traditional eating habits. 
Skin tests with both FM and CM standardized extract are useful in the diagnostic workup of CMPA, but PTP with fresh food extracts were reported to be more effective in detecting sensitization in comparison to SPT with commercial extracts $(14,15)$. With a cut-off of $3 \mathrm{~mm}$ for both allergens tested initially in our group, FM showed more positivity than standardized CM extract similar to previous studies. Mauro et al. (16) reported that PTP with FM showed better sensitivity and NPV than SPT with three milk proteins (a-lactalbumin, casein and b-lactoglobulin), taken singly or all together; however, FM had the least specificity and PPV. Considering the mean age (under six months) of onset in our study group and the wheal size of allergen-induced prick tests which are smaller in infants than in children (due to hyporeactivity), PTP with FM is very useful for the initial diagnostic workup of CMPA, primarily to exclude an IgEmediated CMPA with high sensitivity and NPV (17).

Providing appropriate nutritional guidance is essential to supply sufficient calorie intake, minerals and elements. Non-exclusive breastfeeding of infants with CMPA requires a substitute-formula with age-appropriate nutritional requirements. The type and severity of the clinical reaction and the availability of the formula affect the selection of the formula (2). More than half of the patients in the current study required eHF or AAF, which are recommended by DRACMA guidelines, with eHF as the first line for uncomplicated cases, and AAF for severe cases (9). Although therapeutic CM elimination was achieved with appropriate diet modification by a dietitian, $30 \%$ of the patients in the current study had inadequate vitamin D levels in their blood.

None of the cut-offs for SPT or slgE proposed in the literature can be used to confirm CMPA. However, many reports suggest possible slgE and/or SPT cut-off values for CMPA diagnosis in the pediatric population (18). Different values have been recommended in the literature, even when similar statistical methods are used. CM slgE cut-offs with a 100\% PPV varied between $4.18 \mathrm{KUA} / \mathrm{L}$ and $50 \mathrm{KUA} / \mathrm{L}$ (18). In a group of studies, it was found that casein slgE was the best predictor but in another study CM slgE was a better predictor than the specific IgE for its components (19-22). In the current study, we combined IgE-mediated and mixed hypersensitivity reactions for the analyses of the slgE cutoff for tolerance prediction in patients with CMPA. We found a cut-off level of 7.39 for CM slgE and a cut-off level of 0.56 for casein slgE. In a cohort study, it was reported that among children with CMPA, 70\% of those with a CM slgE < $2 \mathrm{kU} / \mathrm{L}$ had resolved milk allergy compared with only 23\% of those with a CM slgE $>10 \mathrm{kU} / \mathrm{L}$ (5). In the current study analyzing CM slgE level as a categorical variable, subjects with a final CM slgE less than $7.39 \mathrm{kUA} / \mathrm{L}$ had a 9.6-fold increased likelihood of resolving their allergy versus those with levels of greater than $7.39 \mathrm{kUA} / \mathrm{L}$.

No delay in the introduction of complementary feeding in infants with CMPA is recommended for tolerance development in infants and children with CMPA (3). According to our findings, the initiation of complementary feeding was significantly earlier in the tolerant group, which is in accordance with the literature.

The levels of slgE, SPT wheal sizes, sensitization to multiple foods, and a family history of atopy are reported to be inversely associated with the timing of CMPA resolution (3). The levels of slgE, SPT wheal sizes and a family history of atopy were inversely associated with tolerance in the current study. However, there was no significant difference in sensitization to multiple foods. The type of immune reaction in CMPA was shown to be associated with the rate and timing of tolerance acquisition, with more frequent and earlier development of tolerance in non-IgE-mediated CMPA than in IgE-mediated CMPA (23). We found in our study group that the immune tolerance developed more frequently in the non-IgE and mixed group than in IgEmediated CMPA, which is consistent with the literature (4).

The most important limitation of our study is its retrospective design. Selection of the patients for OFC may differ instead of a protocol-defined method. Open OFC was performed for the diagnosis, but it is reported that for the first years of life, open OFC does not seem to cause bias (24). However, the long-term follow-up period and the large number of patients are the strengths of the study reflecting the real-life and clinical course of CMPA in daily practice.

\section{Conclusion}

In this study, we evaluated the natural course of CMPA in a group of children followed up in a pediatric allergy clinic. A significant proportion of these children with CMPA presented as $A D$ in early infancy. In addition to $H E$, tree nuts and wheat, lentil was one of the common coexisting food allergies. The tolerance acquisition rate was more than $50 \%$ by the age of 3 years. IgE-mediated hypersensitivity reactions, family history of atopy, higher slgE values, and the later initiation of complementary feeding were predictors for its persistence.

\section{Acknowledgements}

We would like to thank Prof. Dr. Gülay Başarır from Department of Biostatistics at Mimar Sinan Fine Art 
University for her help with the analysis of the data collected in this project and biostatistical consulting.

\section{Ethics}

Ethics Committee Approval: Ethical approval was received from University of Health Sciences Turkey, Ankara Dr. Sami Ulus Maternity and Children Training and Research Hospital local institutional review board (approval number: 2016/2519).

Informed Consent: Informed consents were not required because the study was conducted retrospectively.

Peer-review: Externally and internally peer-reviewed.

\section{Authorship Contributions}

Concept: A.E., Z.Ş.E., S.Ö., I.B., Design: A.E., I..B., Data Collection or Processing: A.E., Z.Ş.E., I.B., Analysis or Interpretation: A.E., Z.Ş.E., S.Ö., I.B., Literature Search: A.E., Z.Ş.E., Writing: A.E., Z.Ş.E., S.Ö., I.B.

Conflict of Interest: No conflict of interest was declared by the authors.

Financial Disclosure: The authors declared that this study received no financial support.

\section{References}

1. Luyt $D$, Ball $H$, Makwana $N$, et al. BSAClguideline for the diagnosis and management of cow's milk allergy. Clin Exp Allergy 2014; 44:642-72.

2. Guler N, Cokugras FC, Sapan N, et al. Diagnosis and management of cow's milk protein allergy in Turkey: Region-specific recommendations by an expert-panel. Allergol Immunopathol (Madr) 2020; 48:202-10.

3. Sackesen C, Altintas DU, Bingol A, et al. Current trends in tolerance induction in cow's milk allergy: from passive to proactive strategies. Front Pediatr 2019; 7:372.

4. Sánchez-Valverde F, Etayo V, Gil F, et al. Factors Associated with the Development of Immune Tolerance in Children with Cow's Milk Allergy. Int Arch Allergy Immunol 2019; 179:290-6.

5. Wood RA, Sicherer SH, Vickery BP, et al. The natural history of milk allergy in an observational cohort. I Allergy Clin Immunol 2013; 131:805-12.

6. Burks AW, Tang M, Sicherer S, et al. ICON: food allergy. I Allergy Clin Immunol 2012; 129:906-20.

7. Muraro A, Werfel T, Hoffmann-Sommergruber $\mathrm{K}$, et al. $\mathrm{EAACl}$ food allergy and anaphylaxis guidelines: diagnosis and management of food allergy. Allergy 2014; 69:1008-25.

8. Sampson HA, Gerth Van Wijk R, Bindslev-Jensen C, et al. Standardizing double-blind, placebo-controlled oral food challenges: American Academy of Allergy, Asthma \& Immunology -European Academy of Allergy and Clinical Immunology PRACTALL consensus report. I Allergy Clin Immunol 2012; 130:1260-74.

9. Fiocchi A, Brozek I, Schunemann $\mathrm{H}$, et al. World Allergy Organization (WAO) Diagnosis and Rationale for Action against
Cow's Milk Allergy (DRACMA) Guidelines. Pediatr Allergy Immunol 2010; 21:1-125.

10. Bingöl A, Uygun DFK, Akdemir $M$, et al. Cocuklarda Besin Allerjisinin Karakteristik Özellikleri: Ulusal Cok Merkezli Calisma. Asthma Allergy Immunol 2017; 15:10-1.

11. Ayçin $C D$, Altındaş DU. Contribution of the method of diagnosis and the range of IgE -non IgE at cow's milk allergy in daily practice. J Turgut Ozal Med Cent 2016; 23:288-92.

12. Yang $M$, Tan $M$, Wu J, et al. Prevalence, Characteristics, and Outcome of Cow's Milk Protein Allergy in Chinese Infants: A Population-Based Survey. JPEN I Parenter Enteral Nutr 2019; 43:803-8.

13. Novembre E, Vierucci A. Milk allergy/intolerance and atopic dermatitis in infancy and childhood. Allergy 2001; 56:105-8.

14. Calvani M, Alessandri C, Frediani T, et al. Correlation between skin prick test using commercial extract of cow's milk protein and fresh milk and food challenges. Pediatr Allergy Immunol 2007; 18:583-8.

15. Uncuoglu A, Cogurlu MT, Eser Simsek I, Ergul N, Baydemir C, Aydogan M. Predicting outgrowth of IgE-mediated cow's milk allergy: Diagnostic tests in children under two years of age. Allergol Immunopathol (Madr) 2019; 47:449-56.

16. Mauro C, Claudia A, Tullio F, et al. Correlation between skin prick test using commercial extract of cow's milk protein and fresh milk and food challenge. Pediatr Allergy Immunol 2007: 18: 583-588. Pediatr Allergy Immunol 2007; 18:583-8.

17. MCnardo IL, Bousquet J, Rodiere M, Astruc I, Michel FB. Skin test reactivity in infancy. . Allergy Clin Immunol 1985;76:646-51.

18. Cuomo B, Indirli CC, Bianchi A, et al. Specific IgE and skin prick tests to diagnose allergy to fresh and baked cow's milk according to age: a systematic review. Ital / Pediatr 2017; 43:93.

19. Caubet JC, Nowak-Wegrzyn A, Moshier E, Godbold J, Wang J, Sampson HA. Utility of casein-specific IgE levels in pre- dicting reactivity to baked milk. J Allergy Clin Immunol 2013; 131:222-4.

20. D'Urbano LE, Pellegrino K, Artesani MC, et al. Performance of a components-based allergen- microarray in the diagnosis of cow's milk and hen's egg allergy. Clin Exp Allergy 2010; 40:156170 .

21. Castro AP, Pastorino AC, Gushken AK, Kokron CM, Filho UD, Jacob CM. Establishing a cut-off for the serum levels of specific IgE to milk and its components for cow's milk allergy: results from a specific population. Allergol Immunopathol (Madr) 2015; 43:67-72.

22. Ayats-Vidal R, Valdesoiro-Navarrete L, García-González M, Asensio-De la Cruz O, Larramona-Carrera H, Bosque-García M. Predictors of a positive oral food challenge to cow's milk in children sensitized to cow's milk [published online ahead of print, 2020 May 10]. Allergol Immunopathol (Madr) 2020; 48:568-75.

23. Schoemaker AA, Sprikkelman AB, Grimshaw KE, et al. Incidence and natural history of challenge-proven cow's milk allergy in European children-EuroPrevall birth cohort. Allergy 2015; 70:963-72

24. Saarinen KM, Suomalainen H, Savilahti E. Diagnostic value of skin-prick and patch tests and serum eosinophil cationic protein and cow's milk-specific IgE in infants with cow's milk allergy. Clin Exp Allergy 2001; 31:423-9. 